\title{
Gaps in the care of patients admitted to hospital with an exacerbation of chronic obstructive pulmonary disease
}

\author{
Perry P. Choi, Anna Day, Edward Etchells
}

\section{Abstract}

Background: Patients admitted to hospital because of an exacerbation of chronic obstructive pulmonary disease (COPD) are at high risk of adverse events. We evaluated the association between gaps in care and adverse events during the hospital stay and after discharge.

Methods: We retrospectively reviewed the charts of 105 consecutive patients discharged from hospial between Jan. 1 and Dec. 31,2001 , with a diagnosis of COPD exacerbation. On the basis of published guidelines, prior studies and discussions with colleagues, we defined a care gap as having occurred if any of 9 important inpatient and 7 discharge-related processes of care did not take place correctly. Inpatient adverse events included worsening of condition after admission, transfer to a higher level of care, cardiac arrest and death. Dischargerelated adverse events were defined as including readmission to the hospital, revisit to the emergency department or death within 30 days after discharge.

Results: Of the 105 patients studied, 88 (84\%) had at least 1 inpatient gap in care and 16 (15\%) an inpatient adverse event; 2 of the 16 died. Patients who had an inpatient adverse event had more gaps in their care (2.0 v. 1.3 gaps, $\mathrm{p}=0.004)$ and longer stays $(16.4$ v. 8.6 days, $\mathrm{p}=0.007)$. There were 6 adverse events (frequency 38\%) among the 16 patients with 3 or more gaps in their care, 6 adverse events (28\%) among the 21 patients with 2 gaps, 1 adverse event (2\%) among the 51 patients with 1 gap and 3 adverse events (18\%) among the 17 patients with no gaps in their care ( $\mathrm{p}=0.001$ for trend). Of the 103 patients discharged alive, $102(99 \%)$ had at least 1 gap in discharge-related care, but we found no association between these gaps and adverse events within 30 days after discharge.

Interpretation: Gaps in the inpatient care of patients with COPD exacerbation were common and were associated with inpatient adverse events. Gaps in discharge-related care were also common but were not associated with postdischarge adverse events.

CMAJ 2004;170(9):1409-13

$\mathrm{P}$ atients admitted to hospital because of an exacerbation of chronic obstructive pulmonary disease (COPD) account for about $10 \%$ of hospital admissions and represent a substantial portion of hospital costs. ${ }^{1}$ These patients are at high risk of adverse events, including acute respiratory failure, cellulitis, delirium and theo- phylline toxicity, during their hospital stay., ${ }^{2,3}$ They also have high 1-year readmission and postdischarge mortality rates: $25 \%-59 \%{ }^{4-6}$ and $11 \%-22 \%,{ }^{7}$ respectively.

Despite the heavy burden of COPD in acute care hospitals, few studies have explored the relation between quality of inpatient care for COPD and adverse events. One large study found an association between gaps in care and inpatient adverse events, ${ }^{3}$ but this study had several important limitations. Most of the adverse events were related to theophylline toxicity, and theophylline is less commonly used today. The correct temporal relation between the gaps in care and the adverse event was uncertain, because the timing of the adverse event was not known. Finally, a large number of variables were studied, so it was unclear which processes of care should be targeted for improvement.

Our study was designed to determine the frequency of gaps in the care of patients admitted to hospital with a COPD exacerbation and to evaluate the association between gaps in care and inpatient and postdischarge adverse events. We prospectively selected a short list of key processes of care, and we ensured a correct temporal relation between the gaps in care and the adverse events.

\section{Methods}

We carried out a retrospective chart review of consecutive patients discharged from Sunnybrook and Women's College Health Sciences Centre between Jan. 1 and Dec. 31, 2001, with a most responsible diagnosis of COPD exacerbation. This hospital is an academic health sciences centre affiliated with the University of Toronto and has a suburban and urban referral base. Patients discharged with COPD were identified by the following codes of the clinical modification of the International Classification of Diseases (ICD-9-CM): ${ }^{8}$ 490.x (bronchitis, not specified as acute or chronic), 491.x (chronic bronchitis), 492.x (emphysema) and 496.x (chronic airway obstruction, not elsewhere classified [COPD]). Patients were excluded if they were under 50 years of age (because asthma would be the more likely diagnosis), were receiving palliative care or spent their entire stay in the intensive care unit. If a patient was discharged more than once in the study period, only the first discharge was included.

On the basis of input from medical staff and residents, a list of 21 inpatient and 16 discharge-related processes of care was 
generated at our monthly safety rounds, attended by 5 staff internists and about 30 residents and medical students. Published studies, ${ }^{9-13}$ guidelines ${ }^{14-17}$ and clinical judgement of the study investigators (A.D. and E.E.) were used to prospectively specify 9 inpatient and 7 discharge-related processes of care for which gaps were most likely to be associated with inpatient or postdischarge adverse events. We defined a care gap as having occurred if any of these processes of care did not take place correctly. The shortened list was brought back to the monthly safety rounds for verification before data analysis. Data on all 37 processes of care were collected during the chart review, and the reviewer was not aware of which processes would be chosen for the primary analysis.

The study investigators established a graded list of inpatient and postdischarge adverse events before the data were collected. Patients were assigned to the most severe adverse event that occurred during their hospital stay and within 30 days after discharge. Inpatient adverse events (from least to most severe) were worsening of the patient's condition, transfer to the highintensity unit (which offers 2:1 nursing, continuous cardiac monitoring, arterial lines and bilevel positive airway pressure), transfer to the critical care unit, cardiopulmonary arrest ("code blue") and death. Worsening of the patient's condition was assigned if a physician had provided an urgent assessment and orders to intensify cardiopulmonary medications (in terms of frequency, dose or delivery system for bronchodilators) with or without urgent chest radiography.

Adverse events within 30 days after discharge included emergency department revisit because of any respiratory complaint, hospital readmission because of a COPD exacerbation and death. Data collection was limited to revisits and readmissions to our hospital.

Categorical variables were analyzed by $\chi^{2}$ analysis and Fisher's exact test. Continuous variables were compared by means of $t$ tests. The $\chi^{2}$ test for trend was used to examine for a "doseresponse" relation between inpatient gaps in care and inpatient adverse events. Only gaps in care that occurred before the adverse event developed were used in the analysis. We expected that a sample size of 100 would yield sufficiently precise estimates of the frequency of gaps. For processes of care that applied to $100 \mathrm{pa}-$ tients, our estimates would have $95 \%$ confidence intervals (CIs) of $\pm 10 \%$. For processes of care that applied to 30 patients, our estimates would have $95 \%$ CIs of $\pm 16 \%$.

The Sunnybrook and Women's College Research Ethics Board approved the study protocol.

\section{Results}

For the 1-year study period, 125 patients discharged with a most responsible diagnosis of COPD exacerbation were identified. Exclusions $(n=20)$ were due to previous admission because of COPD earlier in the study year $(n=$ $12)$, incorrect coding of COPD $(n=3)$, age less than 50 years $(n=2)$, chart unavailability $(n=2)$ and palliative care $(n=1)$.

Of the 105 patients studied, 88 (84\%) had at least 1 inpatient gap in care. There was a high frequency of gaps for each of the 9 inpatient processes of care examined (Table 1). The most frequent gap related to assessment of the patient's technique in using a metered-dose inhaler within 24 hours after the drug order: $78 \%$ of the 89 patients for whom a metered-dose inhaler was prescribed had no documented assessment of their technique. The least frequent gap was related to $\beta$-blocker therapy: only $3 \%$ of the 105 patients received a new or an increased dosage of $\beta$-blockers.

\section{Table 1: Gaps in inpatient processes of care for patients admitted because} of an exacerbation of COPD

\begin{tabular}{|c|c|c|}
\hline Inpatient process of care & $\begin{array}{l}\text { No. of patients } \\
\text { with gap/no. } \\
\text { eligible for process }\end{array}$ & $\begin{array}{c}\text { Frequency } \\
\text { of gaps, \% } \\
\text { (and } 95 \% \mathrm{Cl} \text { ) }\end{array}$ \\
\hline $\begin{array}{l}\text { Assess patient technique in using metered-dose inhaler(s) within } \\
24 \mathrm{~h} \text { after drug order }\end{array}$ & $69 / 89$ & $78(69-87)$ \\
\hline $\begin{array}{l}\text { Adjust oxygen therapy if } 2 \text { consecutive readings are above ordered } \\
\text { range of oxygen saturation }\end{array}$ & $16 / 25$ & $64(45-83)$ \\
\hline $\begin{array}{l}\text { Give prophylaxis for deep-vein thrombosis if patient is bedridden } \\
\text { for } 2 \text { or more consecutive days }{ }^{11}\end{array}$ & $12 / 27$ & $44(25-63)$ \\
\hline $\begin{array}{l}\text { Write order to keep oxygen saturation within lower range } \\
\text { (e.g., } 85 \%-92 \% \text { ) if } \mathrm{pH} \text { is }<7.45 \text { and arterial partial pressure of } \\
\text { carbon dioxide is }>45 \mathrm{~mm} \mathrm{Hg} \mathrm{Hg}^{16}\end{array}$ & $11 / 36$ & $31(16-46)$ \\
\hline $\begin{array}{l}\text { Measure arterial blood gases if admission bicarbonate level is } \\
>30 \mathrm{mmol} / \mathrm{L} \text { (within } 24 \mathrm{~h} \text { ) }\end{array}$ & $9 / 31$ & $29(13-45)$ \\
\hline $\begin{array}{l}\text { Measure arterial blood gases if admission oxygen saturation is } \\
\leq 90 \% \text { while patient is breathing room air (within } 24 \mathrm{~h} \text { ) }\end{array}$ & $11 / 41$ & $27(13-41)$ \\
\hline Do not order new or increased dosage of sedatives by telephone ${ }^{9}$ & $13 / 105$ & $12(6-18)$ \\
\hline $\begin{array}{l}\text { Order appropriate antibiotics if } 2 \text { of the following } 3 \text { symptoms are } \\
\text { present: increased dyspnea, increased sputum volume, increased } \\
\text { sputum purulence }\end{array}$ & $4 / 73$ & $5(0-10)$ \\
\hline Do not order new or increased dosage of $\beta$-blockers ${ }^{10}$ & $3 / 105$ & $3(0-6)$ \\
\hline
\end{tabular}

Note: $\mathrm{COPD}$ = chronic obstructive pulmonary disease, $\mathrm{Cl}$ = confidence interval. 
There were 16 patients with inpatient adverse events (frequency 15\%), including worsening of condition (10), transfer to the high-intensity unit (3), death (2) and cardiopulmonary arrest (1). Urgent chest radiography was ordered for 9 of the patients whose condition worsened. The mean number of inpatient days before the adverse event was 6.

Patients with inpatient adverse events had more gaps in care than patients without such events $(2.0 \mathrm{v} .1 .3, p=0.004)$. There was a significant association between the number of gaps and inpatient adverse events $\left(\chi^{2}\right.$ test for trend, $p=$ 0.001 ). There were 6 adverse events (frequency $38 \%$ ) among the 16 patients with 3 or more gaps in their care, 6 adverse events (28\%) among the 21 patients with 2 gaps, 1 adverse event (2\%) among the 51 patients with 1 gap and 3 adverse events (18\%) among the 17 patients with no gaps in their care. In addition, the mean hospital stay was significantly longer for patients with an inpatient adverse event than for those without one (16.4 v. 8.6 days, $p=0.007)$. Characteristics of the patients with and without inpatient adverse events are listed in Table 2; no statistically significant differences between the groups were identified.

The mean hospital stay before the inpatient adverse event was 6 days, whereas the mean stay for patients discharged without adverse events was 8.6 days. Therefore, patients without adverse events had a greater opportunity to experience gaps in care during their hospital stay. $\mathrm{Pa}$ - tients with an inpatient adverse event had a mean of 0.39 gaps per day in hospital before the adverse event, whereas patients without an adverse event had a mean of 0.23 gaps per day (difference -0.16 gaps per admission day; $95 \%$ CI -0.34 to $0.03 ; p=0.09$ ).

We conducted 2 exploratory analyses to assess the potential confounding role of disease severity. First, we classified the patient's condition as "severe" if 1 or more of the following features applied: previous admission to a critical care unit because of COPD exacerbation within the previous year, previous admission to hospital because of COPD exacerbation within the previous year, home oxygen use, home steroid use, or oxygen saturation of $90 \%$ or less while the patient was breathing room air at the time of admission. Among the patients whose condition was classified as severe, those with inpatient adverse events $(n=12)$ had more gaps in care than those without such events $(n=62)$ (2.2 v. 1.5 gaps; relative increase $47 \%, p=0.02$ ). Among the patients whose condition was classified as not severe, those with inpatient adverse events $(n=4)$ also had more gaps than those without such events $(n=27)(1.5$ v. 0.8 ; relative increase $88 \%, p=0.04)$. Second, patients with more severe illness required more processes of care, so they had more opportunity to experience a gap. Patients with an inpatient adverse event had 0.34 gaps per opportunity, whereas patients without such an event had 0.25 gaps per opportunity (36\% increase, $p=0.12$ ).

\begin{tabular}{|c|c|c|c|}
\hline Characteristic & $\begin{array}{c}\text { Patients with an } \\
\text { inpatient adverse event } \\
n=16\end{array}$ & $\begin{array}{l}\text { Patients without an } \\
\text { inpatient adverse event } \\
\qquad n=89\end{array}$ & $p$ value \\
\hline Mean age (and standard deviation), yr & $76(11)$ & $77 \quad(9)$ & 0.68 \\
\hline Female, no. (and \%) & $8 \quad(50)$ & $48(54)$ & 0.77 \\
\hline \multicolumn{4}{|l|}{ Residence, no. (and \%) } \\
\hline Lives alone in community & $5 \quad(31)$ & $29(32)$ & \\
\hline Lives with someone in community & $11(69)$ & $50(56)$ & \\
\hline Not documented & 0 & $10(11)$ & 0.34 \\
\hline \multicolumn{4}{|l|}{ Disease severity, no. (and \%) } \\
\hline Current smoker & $5(31)$ & $22(25)$ & 0.60 \\
\hline Using oxygen at home & $4(25)$ & $24(27)$ & 1.0 \\
\hline Using steroids orally at home & $5(31)$ & $22(25)$ & 0.60 \\
\hline $\begin{array}{l}\text { Admission oxygen saturation } \leq 90 \% \text { while } \\
\text { breathing room air }\end{array}$ & $7 \quad(44)$ & $34(38)$ & 0.68 \\
\hline $\begin{array}{l}\text { Visited emergency department because of } \\
\text { any respiratory complaint in previous year* }\end{array}$ & $2(12)$ & $13(15)$ & 1.0 \\
\hline $\begin{array}{l}\text { Admitted to hospital because of COPD } \\
\text { exacerbation in previous year* }\end{array}$ & $4 \quad(25)$ & $15(17)$ & 0.48 \\
\hline $\begin{array}{l}\text { Admitted to intensive care unit for any } \\
\text { reason in previous year* }\end{array}$ & $1 \quad(6)$ & $4 \quad(4)$ & 0.57 \\
\hline \multicolumn{4}{|l|}{ Comorbidity, no. (and \%) } \\
\hline History of any cardiovascular problem† & 14 (88) & $59(66)$ & 0.14 \\
\hline Diabetes & $2(12)$ & $12(13)$ & 1.0 \\
\hline
\end{tabular}

* This includes visits or admissions to any institution if documented in the admission history and any admission to our hospital identified from the admission database.

tIncludes coronary artery disease, hypertension, myocardial infarction and peripheral vascular disease. 
Of the 103 patients who were discharged, 102 (99\%) had at least 1 gap in their care. There was also a high frequency of gaps for each of the 7 discharge-related processes of care examined (Table 3). By 30 days after discharge, there had been 10 discharge-related adverse events (frequency 10\%): 7 hospital readmissions because of a COPD exacerbation, 2 emergency department revisits because of a respiratory complaint and 1 death during a readmission. The 10 patients with a discharge-related adverse event had a mean of 2.0 discharge-related gaps in care, whereas those without such an event had a mean of 2.5 discharge-related gaps. The difference, -0.5 gaps, was not significant $(95 \%$ CI -1.2 to $0.3, p=0.22$ ).

\section{Interpretation}

We found that inpatient and discharge-related gaps in care were common and that inpatient gaps were significantly associated with inpatient adverse events. We also detected a dose-response relation between inpatient gaps and inpatient adverse events. Finally, we found that patients with inpatient adverse events had a significantly longer stay in hospital. We also found a high frequency of gaps in discharge-related care, but we did not find an association between these gaps and adverse events within 30 days after discharge.

Our results are consistent with those in the prior study that found frequent gaps in the care of patients with COPD and an association between gaps and inpatient adverse events. ${ }^{3}$ Unlike that study, ours did not demonstrate an association between gaps in care and dischargerelated adverse events. However, our study identified relatively few discharge-related adverse events, and we may have missed events that led patients to go to other hospitals.

Our conclusions have some important limitations. First, adverse events are also associated with age, comorbidity and disease severity. ${ }^{2,3}$ Our retrospective measures of comorbidity and disease severity were limited, and multivari- ate analyses were not possible on the data from our small sample. However, the observed association between gaps and adverse events was consistent for the subgroups of patients with severe and less severe COPD and was not explained by differences in either length of hospital stay before the event or opportunity to experience gaps.

Another limitation is that we relied on documentation as evidence that the care was given. It is possible, for example, that the health care team properly assessed inhaler technique but did not document their efforts. However, house staff physicians and nurses have been shown to have poor knowledge of and ability to use inhaling devices. ${ }^{18}$ Only $20 \%$ of COPD and asthma patients correctly administer their medications, ${ }^{19-22}$ and elderly patients with cognitive impairment and poor hand strength are most likely to have difficulties. ${ }^{23}$ Therefore, even if we overestimated the gaps in assessing bronchodilator technique, we doubt that the patients were receiving effective bronchodilator therapy.

Our study adds to existing evidence of significant gaps in inpatient COPD care. The usual response to such data is to remind clinicians to be smarter and more careful, but such reminders may not result in better care. Rather, we need to adopt some new methods of enquiry, possibly from safety science, to understand the systematic causes for these gaps better. Systematic, safety-oriented evaluations of adverse drug events ${ }^{24}$ led to the development of successful interventions such as computerized order entry by physicians ${ }^{25}$ and pharmacist participation in patient care rounds. ${ }^{26}$

In summary, we found that gaps in the care of inpatients with a most responsible diagnosis of COPD were common and were associated with inpatient adverse events. We also found discharge-related gaps to be common, but we did not detect an association between these gaps and discharge-related adverse events. Our results should encourage others to examine the care of their COPD patients and to uncover the systematic causes of these gaps in care.

Table 3: Gaps in discharge-related processes of care

\begin{tabular}{lcc}
\hline Discharge-related process of care & $\begin{array}{c}\text { No. of patients } \\
\text { with gap/no. } \\
\text { eligible for process }\end{array}$ & $\begin{array}{c}\text { Frequency of } \\
\text { gaps, \% (and } \\
95 \% \text { Cl) }\end{array}$ \\
\hline $\begin{array}{l}\text { Measure oxygen saturation with exertion before discharge if level } \\
\text { is }<92 \% \text { while patient is breathing room air }\end{array}$ & $\begin{array}{c}8 / 11 \\
\text { If inhaler is prescribed at discharge, educate patient on its use }\end{array}$ & $73(46-100)$ \\
$\begin{array}{l}\text { Make follow-up appointment with any physician (family physician } \\
\text { or specialist) for specific date and time }\end{array}$ & $72(63-81)$ \\
$\begin{array}{l}\text { If patient is going home, order home-care assessment } \\
\text { Observe patient in hospital for at least } 24 \text { h after a change in }\end{array}$ & $74 / 103$ & $72(63-81)$ \\
$\begin{array}{l}\text { bronchodilator system before discharge } \\
\text { Prescribe oral or inhaled steroid therapy at discharge }\end{array}$ & $48 / 81$ & $59(48-70)$ \\
$\begin{array}{l}\text { Ensure that oxygen saturation at rest is }>90 \% \text { before discharge } \\
\text { (if being measured while patient is breathing room air) }\end{array}$ & $23 / 65$ & $35(23-47)$ \\
\hline
\end{tabular}


This article has been peer reviewed.

From the Department of Medicine, Sunnybrook and Women's College Health Sciences Centre and University of Toronto, Toronto, Ont.

Competing interests: Anna Day has served on advisory boards with Boehringer Ingelheim (Canada) Ltd. and GlaxoSmithKline and has performed clinical research with Boehringer Ingelheim and AstraZeneca Canada Inc.

Contributors: Perry Choi collected, analyzed and interpreted the data, drafted the initial manuscript and revised important content of the manuscript. Anna Day and Edward Etchells conceived the study, supervised data collection, planned the data analysis, interpreted the results and revised important content of the manuscript. All authors approved the version submitted for publication.

Acknowledgements: We gratefully acknowledge the input of the medical house staff and staff physicians of the general medicine clinical teaching units at Sunnybrook and Women's College Health Sciences Centre for their contribution to defining the processes of care. We thank Drs. Donald Redelmeier and Steven Shumak for commenting on earlier drafts of the article.

This work was supported by the Summer Studentship Program of the Department of Medicine, and the Innovations Fund, Sunnybrook and Women's College Health Sciences Centre.

\section{References}

1. Canadian Institute for Health Information, Canadian Lung Association, Health Canada, Statistics Canada. Respiratory disease in Canada. Ottawa: Health Canada;2001.

2. Geraci JM, Ashton CM, Kuykendall DH, Johnson ML, Wu L. In-hospital complications among survivors of admission for congestive heart failure, chronic obstructive pulmonary disease, or diabetes mellitus. 7 Gen Intern Med 1995;10:307-14.

3. Geraci JM, Ashton CM, Kuykendall DH, Johnson ML, Souchek J, del Junco $\mathrm{D}$, et al. The association of quality of care and occurrence of in-hospital, treatment-related complications. Med Care 1999;37:140-8.

4. Sin DD, Tu JV. Inhaled corticosteroids and the risk of mortality and readmission in elderly patients with chronic obstructive pulmonary disease. $A m \mathcal{F}$ Respir Crit Care Med 2001;164:580-4.

5. Osman LM, Godden DJ, Friend JAR, Legge JS, Douglas JG. Quality of life and hospital re-admission in patients with chronic obstructive pulmonary disease. Thorax 1997;52:67-71.

6. Lau ACW, Yam LYC, Poon E. Hospital re-admission in patients with acute exacerbation of chronic obstructive pulmonary disease. Respir Med 2001;95:876-84.

7. Almagro P, Calbo E, Ochoa de Echaguen A, Barreiro B, Quintana S, et al Mortality after hospitalization for COPD. Chest 2002;121:1441-8.

8. International classification of diseases, 9th rev. (clinical modification). 5th ed. Washington: US Department of Health and Human Services; 1996.

9. George CF, Bayliff CD. Management of insomnia in patients with chronic obstructive pulmonary disease. Drugs 2003;63:379-87.

10. Salpeter SS, Ormiston T, Salpeter E, Poole P, Cates C. Cardioselective betablockers for chronic obstructive pulmonary disease [Cochrane review]. In The Cochrane Library; Issue 1, 2003. Oxford: Update Software.

11. Geerts WH, Heit JA, Clagett GP, Pineo GF, Colwell CW, Anderson FA Jr, et al. Prevention of venous thromboembolism. Chest 2001;199:132S-75S.

12. Sin DD, Bell NR, Svenson LW, Man SFP. The impact of follow-up physician visits on emergency readmissions for patients with asthma and chronic obstructive pulmonary disease: a population-based study. Am 7 Med 2002;112:120-5.

13. Narsavage GL, Naylor MD. Factors associated with referral of elderly individuals with cardiac and pulmonary disorders for home care services following hospital discharge. 7 Gerontol Nurs 2000;26(5):14-20.

14. Pauwels RA, Buist AS, Calverley PMA, Jenkins CR, Hurd SS. Global strategy for the diagnosis, management, and prevention of chronic obstructive pulmonary disease. NHLBI/WHO Global Initiative for Chronic Obstructive Lung Disease (GOLD) Workshop Summary. Am 7 Respir Crit Care Med 2001;163: 1256-76.

15. Canadian Respiratory Review Panel. Guidelines for the treatment of chronic obstructive pulmonary disease. 1st ed. Toronto: Medication Use Management Services; 1998.

16. COPD Guidelines Group of the Standards of Care Committee of the BTS BTS guidelines for the management of chronic obstructive pulmonary disease. Thorax 1997;52(S5):S1-28.

17. Snow V, Lascher S, Mottur-Pilson C. Evidence base for management of acute exacerbations of chronic obstructive pulmonary disease. Ann Intern Med 2001;134: 595-9.

18. Hanania NA, Wittman R, Kesten S, Chapman KR. Medical personnel's knowledge of and ability to use inhaling devices. Metered-dose inhalers, spacing chambers, and breath-actuated dry powder inhalers. Chest 1994;105:111-6.

19. Larsen JS, Hahn M, Ekholm B, Wick KA. Evaluation of conventional press-andbreathe metered-dose inhaler technique in 501 patients. F Astbma 1994;31:193-9.

20. Van Beerendonk I, Mesters I, Mudde AN, Tan TD. Assessment of the inhalation technique in outpatients with asthma or chronic obstructive pulmonary disease using a metered-dose inhaler or dry powder device. 7 Asthma 1998;35:273-9.

21. Shrestha M, Parupia H, Andrews B, Kim SW, Martin MS, Park DI, et al Metered-dose inhaler technique of patients in an urban ED: prevalence of incorrect technique and attempt at education. Am 7 Emerg Med 1996;14:380-4.

22. Johnson DH, Robart P. Inhaler technique of outpatients in the home. Respir Care 2000;45:1182-7.

23. Gray SL, Williams DM, Pulliam CC, Sirgo MA, Bishop AL, Donohue JF Characteristics predicting incorrect metered-dose inhaler technique in older subjects. Arch Intern Med 1996;156:984-8.

24. Leape LL, Bates DW, Cullen DJ, Cooper J, Demonaco HJ, Gallivan T, et al. Systems analysis of adverse drug events. ADE Prevention Study Group. 7AMA 1995;274:35-43.

25. Bates DW, Teich JM, Lee J, Seger D, Kuperman GJ, Ma'Luf N, et al. The impact of computerized physician order entry on medication error prevention. 7 Am Med Inform Assoc 1999;6:313-21.

26. Leape LL, Cullen DJ, Clapp MD, Burdick E, Demonaco HJ, Erickson JI, et al. Pharmacist participation on physician rounds and adverse drug events in the intensive care unit. $\mathcal{F} A M A 1999 ; 282: 267-70$.

Correspondence: Dr. Edward Etchells, Director, Patient Safety Service, Sunnybrook and Women's College Health Sciences Centre and University of Toronto, 2075 Bayview Ave., Rm. C410, Toronto ON M4N 3M5; edward.etchells@sw.ca 